\title{
Biological attributes of the kissing bug Triatoma rubrofasciata from Vietnam
}

\author{
Ho Viet Hieu' ${ }^{1}$, Le Thanh Do ${ }^{2 *}$, Sebastián Pita ${ }^{3}$, Hoang Ha ${ }^{1}$, Pham Thi Khoa ${ }^{1}$, Pham Anh Tuan ${ }^{1}$, Ta Phuong Mai ${ }^{1}$, \\ Ngo Giang Lien ${ }^{4}$ and Francisco Panzera ${ }^{3^{*}}$
}

\begin{abstract}
Background: Triatoma rubrofasciata is the only kissing bug species distributed globally. In the Americas, this species transmits the parasite Trypanosoma cruzi, responsible for Chagas disease. The presence of T. rubrofasciata in several Asian countries has greatly increased recently. In Vietnam, it is found in large numbers, closely associated with human environments. Although T. rubrofasciata from Asia is not infected with Tryp. cruzi, it carries other parasites such as Trypanosoma lewisi and Trypanosoma conorhini. Reports of bites by T. rubrofasciata have increased significantly in several places of Vietnam, becoming a public health problem as it produces severe anaphylactic reactions.
\end{abstract}

Methods: Specimens of T. rubrofasciata were collected from seven provinces in central Vietnam. We analyzed different biological attributes (life-cycle, starvation resistance, feeding and reproductive capacities) and genetic characteristics (chromosomes and DNA sequences) of T. rubrofasciata from Vietnam and compared them with Brazilian specimens. Natural infection with Tryp. conorhini and Tryp. lewisi were analyzed in a sample of 100 collected insects.

Results: Species identification of T. rubrofasciata from central Vietnam was corroborated by genetic markers. Cytogenetic analyses showed that T. rubrofasciata from central Vietnam share the same chromosomal characteristics with individuals from Brazil and Hanoi. DNA sequence analyses of a mitochondrial cytochrome b gene fragment showed little variation between Old and New World specimens. Our study sample, compared with Brazilian individuals, showed a higher survival capacity revealed by a higher hatching rate ( $98 \%$ compared with $80.5 \%$ ), a larger amount of blood taken in single meal and long-term starvation resistance. Furthermore, this species had a high natural rate of infection with Tryp. conorhini (46\%) and Tryp. lewisi (27\%).

Conclusions: For T. rubrofasciata of Vietnam, a high rate of fecundity throughout the year, a high capacity for starvation, and its occurrence in synanthropic environments of urban areas with a high availability of food sources are risk factors to be taken into account by vector control campaigns. The several allergic reactions caused by their bites and their high infection with Tryp. lewisi highlight the need to implement specific control programmes for T. rubrofasciata in Vietnam.

Keywords: Asia, Blood-sucking bug, Triatoma rubrofasciata, Trypanosoma conorhini, Trypanosoma lewisi, Vietnam

\footnotetext{
*Correspondence: lethanhdo1@duytan.edu.vn; panzera@fcien.edu.uy

${ }^{2}$ Institute for Global Health Innovations, Duy Tan University, Da

Nang 550000, Vietnam

${ }^{3}$ Sección Genética Evolutiva, Facultad de Ciencias, Universidad de la

República, 11400 Montevideo, Uruguay

Full list of author information is available at the end of the article
}

(c) The Author(s) 2019. This article is licensed under a Creative Commons Attribution 4.0 International License, which permits use, sharing, adaptation, distribution and reproduction in any medium or format, as long as you give appropriate credit to the original author(s) and the source, provide a link to the Creative Commons licence, and indicate if changes were made. The images or other third party material in this article are included in the article's Creative Commons licence, unless indicated otherwise in a credit line to the material. If material is not included in the article's Creative Commons licence and your intended use is not permitted by statutory regulation or exceeds the permitted use, you will need to obtain permission directly from the copyright holder. To view a copy of this licence, visit http://creativecommons.org/licenses/by/4.0/. The Creative Commons Public Domain Dedication waiver (http://creativecommons.org/publicdomain/zero/1.0/) applies to the data made available in this article, unless otherwise stated in a credit line to the data. 


\section{Background}

Triatoma rubrofasciata is a hemipteran insect of the subfamily Triatominae. There are around 150 triatomine species worldwide, most of them vectors of Trypanosoma cruzi, causative agent of Chagas disease in the Americas [1]. Of these species, only T. rubrofasciata is found in both New and Old Worlds [2], having been reported in many localities in Asia, Africa, the Americas (South, Central and North America), islands of the Indian Ocean, Pacific Ocean and the Azores in the Atlantic Ocean [1, $3]$. However, in this century the occurrence of this species in the Americas has been restricted to coastal cities from Brazil. A national survey among 2004-2008 showed that in the Brazilian State of Maranhão, T. rubrofasciata represented more than $90 \%$ of the insects captured inside the homes [4]. In other South American countries such as French Guiana or Venezuela, T. rubrofasciata has not been found in the last 20 years [5]. On the contrary, the presence of T. rubrofasciata in Asia has increased in recent years, having been reported in China [6-8], Vietnam [3], India [9] and Sri Lanka [10]. In Vietnam, a national survey during the period 2010-2012 showed that $T$. rubrofasciata is found in at least 21 provinces, involving large cities such as Hanoi and Ho Chi Minh [3]. Urban infestations involve hundreds of insects per house, with a seasonal peak of adult bugs from June to September. Although T. rubrofasciata from Asia is not infected with Tryp. cruzi, it is frequently feeding on humans, causing severe bite reactions that sometimes lead to anaphylactic shock [3, 7-12].

In recent years, reports of bites of T. rubrofasciata to the human population have increased significantly in different places of Vietnam, becoming a public health problem $[3,13]$. Bitten people present swelling and itching at the site of the bite, sometimes with a local skin infection. In Hanoi, $24 \%$ of the cases also involved a severe fever that lasted between one and two days [13]. Therefore, it is highly important to control T. rubrofasciata populations in order to avoid human attacks. For this reason, understanding of the biology of this species in Asia is indispensable [14].

Trypanosoma conorhini and Tryp. lewisi are extracellular kinetoplastid parasites of mammals, evolutionary close to Tryp. cruzi $[15,16]$. Both are obligatory parasites of rodents of the genus Rattus with a worldwide distribution [17]. The cycle of Tryp. conorhini on T. rubrofasciata as vector has been documented long ago $[17,18]$. Although there are no reports of human infection with Tryp. conorhini, several authors have demonstrated experimental infection in mice and non-human primates [19]. Trypanosoma lewisi is transmitted by rat fleas of genera Nosopsyllus and Xenopsylla [20] and traditionally it was considered as non-pathogenic to its natural hosts and humans [17]. However, several cases of human infection, including fatal ones, have been reported mainly in India [21-23] where T. rubrofasciata has been found [9]. As far as we know, this would be the first report of triatomine infection with Tryp. lewisi.

In the present study, T. rubrofasciata specimens were collected in several rural and urban areas from central Vietnam during 2014-2016. The collected individuals were identified as T. rubrofasciata following the morphological keys traditionally applied for triatomine species identification [1] as well as two genetic markers. We determined different biological attributes of Asian $T$. rubrofasciata and compared them with individuals from Brazil. Furthermore, a sample of one hundred individuals was scanned for natural infection with trypanosomatid parasites.

\section{Methods}

\section{Triatomine collection and breeding}

Triatomine bugs (891 eggs, 394 nymphs in all stages and 559 adults) were caught in both urban and rural areas from seven provinces in central Vietnam. The morphological and chromatic characteristics in the individuals collected were the same as those described in specimens from southern China [6-8]. Most of them were collected in two cities, Da Nang and Quy Nhon, during July 2014 to July 2016. The majority of the nymphs and adults were sacrificed for detection of parasites, while hatched eggs were used to establish the Da Nang laboratory colony. The laboratory conditions (humidity, temperature and light) were not controlled during the study. Bugs were kept in masked buckets and fed on live chickens weekly.

\section{Genetic studies}

Cytogenetic analyses were performed on fourteen male T. rubrofasciata specimens collected from Da Nang city. Testes were removed from freshly killed adults, fixed in an ethanol:acetic acid mixture $(3: 1)$ and stored at $-20^{\circ} \mathrm{C}$. Chromosomal slides were obtained using the squashing method [24]. Briefly, small pieces of samples were transferred into $50 \%$ acetic acid drops. Squashes were made, the coverslips were removed, and the slides were left dried to proceed or stored at $4{ }^{\circ} \mathrm{C}$. The C-banding technique [24] was used in order to determine the chromosome number and the distribution and behavior of C-heterochromatin during mitosis and meiosis. Fluorescent in situ hybridization (FISH) was carried out on 2 males [25] in order to determine the chromosomal location of $45 \mathrm{~S}$ ribosomal DNA clusters. Slides were analyzed using a Nikon Eclipse 80i epifluorescence microscope (Nikon, Tokyo, Japan). Images were captured with a Nikon DS-5Mc-U2 digital cooled camera using Nikon Nis Elements 3.1 Advanced Research software, 
and processed with Adobe Photoshop ${ }^{\circledR}$ software. The C-banding pattern for each specimen was determined by analyzing at least 10 cells, both in mitotic (spermatogonial prometaphase) and or meiotic plates (metaphase I or II).

Two adult individuals from Da Nang city were analyzed using the mitochondrial cytochrome $b$ gene fragment $(c y t b)$. DNA was extracted from each individual using three legs fixed in $70 \%$ ethanol. Total DNA was isolated by standard phenol-chloroform techniques, resuspended in $50 \mu \mathrm{l}$ and stored at $-20{ }^{\circ} \mathrm{C}$ until use. For each specimen, a cytb 561bp-fragment was PCR amplified [26]. PCR products were sent to Macrogen Inc. (Macrogen Inc., Seoul, Korea) for sequencing. For both samples, sequencing was conducted in forward and reverse directions. In addition, an NCBI BLAST search was performed in order to compare our samples with $T$. rubrofasciata sequences available on GenBank. Alignments were performed using MAFFT v7.310 [27]. To infer the basic population statistics and the genetic distances of the haplotypes, under Kimura 2-parameter model, we used R packages Ape [28] and Pegas [29]. First, all DNA sequences were loaded into $R$ using read.dna function. Then, haplotypes were assessed using the haplotype function (nuc.div, hap.div and dist.dna for nucleotide diversity, haplotype diversity and genetic distances, respectively). Additionally, haplotype sequences were used to construct a network, using the function haploNet in the R package Pegas [29]. We plotted the haplotype network using the normal $\mathrm{R}$ plot function.

\section{Feeding capacity}

To determine the amount of blood that an insect absorbs in each stage of its development, thirty insects from each nymphal instar were kept separated in cubes. Those insects that hatched or molted within three days were transferred to other cubes and weighed before and after their first meal after hatching or molting. The weight of the insects before and after feeding was measured and compared to assess feeding capacity (weights of taken bloods to hungry weights).

\section{Reproductive capacity}

Ten adult couples were kept in separate cubes throughout their lives. The number of eggs produced by each couple every $24 \mathrm{~h}$ was recorded to calculate the minimum and maximum number of eggs produced by a single female in a single day and throughout her life. Ten couples of adults were randomly selected each month and kept as groups to investigate the seasonal-dependent reproductive capacity.

\section{Starvation resistance}

After egg hatching (nymph first-instar) or molting (other stages), bugs were not provided food and were left to die. The date of hatching/molting and date of death were recorded to calculate starvation resistance.

\section{Size of bugs and life-cycles}

The eggs that were produced and bugs that hatched or molted on same day were kept in separate buckets and fed weekly on live chickens until next molting or death. When the first bug in one group was undergoing molting to become a new nymph or adult, the size (width and length) of the other bugs in the same group was measured. In adult groups, when $50 \%$ of the females in one group produced eggs, the size of all members of the group was measured. Minimum and maximum time for egg maturation, development of each nymphal instar and living duration of adults were also recorded. The data of 30 nymphs at each instar and 60 adults ( 30 males and 30 females) were collected.

\section{Bug infection with Trypanosoma species}

Microscope identification of Tryp. conorhini and Tryp. lewisi was made according to $[18,21]$, respectively.

\section{Results \\ Collection sites of $T$. rubrofasciata in central Vietnam}

All bugs (1844 including eggs) were caught in both urban (15 sites) and rural areas (7 sites). In 14 collection sites (9 urban and 5 rural) abundant bug nests were found including numerous eggs and bugs at all stages. In the remaining 8 sites ( 6 urban and 2 rural) only adults were found. In domestic environments, the beds, walls and roof cracks were the collection sites. In these habitats, no other food sources for insects were detected than the residents of the houses themselves. In urban and rural areas, peridomestic bug nests were found mostly in firewood storage places, wooden floors or cleft walls. In peridomestic structures, the bugs were mainly associated with rats (Rattus norvegicus) and in a smaller proportion with domestic mice. In rural environments, insects were also found associated with domestic animals such as cows or buffalos, pigs and chickens. In the regions of collection, triatomine bugs bites with anaphylactic shock have been reported. In all field trips to wild areas (far from human housing), we failed to collect bugs.

Of the 145 bugs collected inside houses (with people living there) in Da Nang city, $60 \%$ were captured on the ground floor, while only $22.07 \%$ of the bugs were captured on the first floor (Fig. 1). Few bugs were collected on second, third, fourth or fifth floors and none of them 


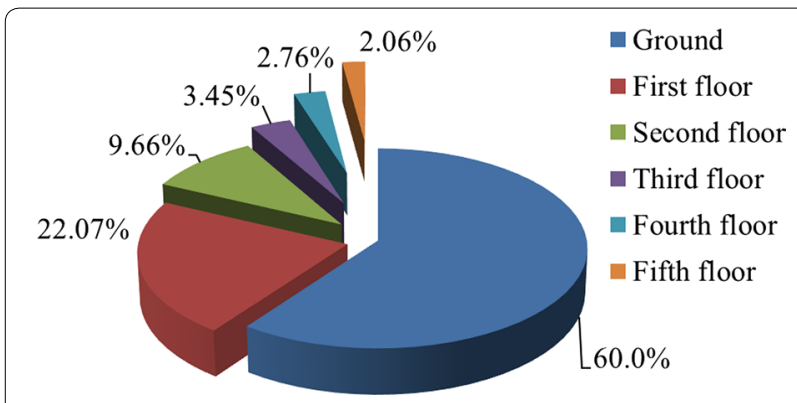

Fig. 1 Scheme showing the distribution of individuals of $T$. rubrofasciata in urban dwellings collected on different floors

found on the sixth floor of the buildings. Additionally, abandoned houses and buildings provided a good environment for T. rubrofasciata within the city, with several very large nests including numerous eggs and bugs at all stages. The individuals collected from abandoned houses are not included in this study.

\section{Morphological and genetic identification}

The individuals collected were identified as T. rubrofasciata following the morphological keys traditionally applied for triatomine species identification [1] with external characteristics similar to individuals from China [6-8].

Chromosomal analyses in all individuals showed a male diploid chromosome number of 25 chromosomes (22 autosomes plus 3 sex chromosomes: $\mathrm{X}_{1}, \mathrm{X}_{2}$ and Y) (Fig. 2). The eleven autosomal pairs had C-heterochromatic blocks in both chromosomal ends. The $\mathrm{Y}$ sex chromosome was totally heterochromatic, while the $\mathrm{X}_{1}$ and $\mathrm{X}_{2}$ sex chromosomes were the smallest of the complement (Fig. 2a, b). FISH technique indicated that $45 \mathrm{~S}$ ribosomal DNA clusters were located in the largest autosomal pair (Fig. 2c).
The $c y t b$ sequences analyzed for both individuals from central Vietnam (Da Nang) were identical (GenBank: MN215889). Moreover, the BLAST search using these $c y t b$ sequences retrieved 14 matches, belonging to $T$. rubrofasciata individuals collected in China (several locations), Taiwan, Brazil and Vietnam (Hanoi). Considering the 14 sequences available on GenBank, plus the 2 individuals analyzed in this paper, a total of six haplotypes were identified (Fig. 3, Additional file 1: Tables S1, S2). In the $488 \mathrm{bp}$ alignment, 8 sites were variable. The most frequent haplotype (I) was present in China (Guangxi, Hainan), Taiwan and Vietnam (Hanoi and Da Nang). Guangxi (China) was the location which presented most haplotype variation.

Nucleotide diversities were low, as expected for an intraspecific variation, and also comparable with the values usually reported for other triatomines (Additional file 1: Tables S1, S2). The largest genetic distance between T. rubrofasciata haplotypes was 0.013 between haplotype IV with haplotypes II, III and VI (Additional file 1: Table S2), as shown in Fig. 3. However, as this species possesses a trans-continental distribution, it is noteworthy that individuals located in Brazil and China (Guangxi) shared the same haplotype (V).

\section{Size, color and egg hatching}

The newly produced eggs were $1.79 \pm 0.139 \mathrm{~mm}$ long and $0.91 \pm 0.089 \mathrm{~mm}$ wide, and had a milky-white color (Fig. 4a). During their development, the eggs changed color to orange-yellow on days 3-4 (Fig. 4b) and to pink on day 7 (Fig. 4c). The eyes of the insects could be seen on day 3 , and they turned reddish before hatching (day 10 onwards). At the time of hatching, the insect pushes the operculum open, enabling it to leave (Fig. 4d), leaving the egg shells transparent (Fig. 4e). A very low frequency of non-hatched eggs was detected due to unformed
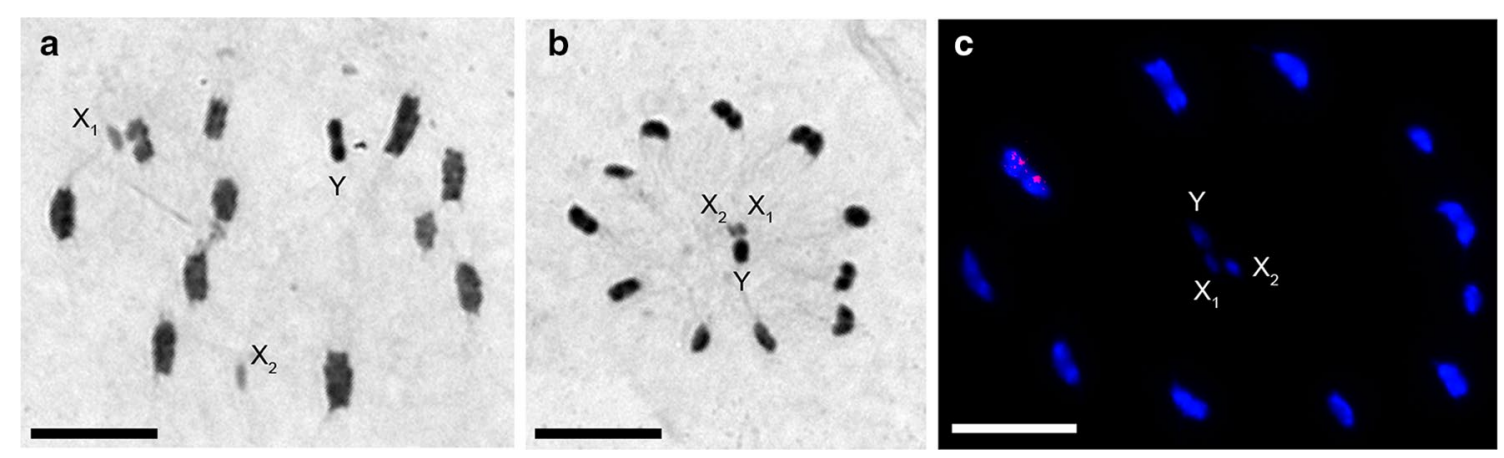

Fig. 2 Meiotic chromosomes of T. rubrofasciata from Central Vietnam. a Metaphase I with C-banding. Eleven autosomal pairs and three sex chromosomes are clearly observed. b Metaphase II with C-banding. Typical spatial configuration of triatomines, with the autosomes forming a ring around the sex chromosomes that are arranged in the center. c Metaphase II. Fluorescent in situ hybridization with 455 ribosomal DNA probe. The $45 \mathrm{~S}$ rDNA signals are located in the largest autosomal pair (red signals). Scale-bars: a $10 \mu \mathrm{m} ; \mathbf{b} 10 \mu \mathrm{m} ; \mathbf{c} 10 \mu \mathrm{m}$ 


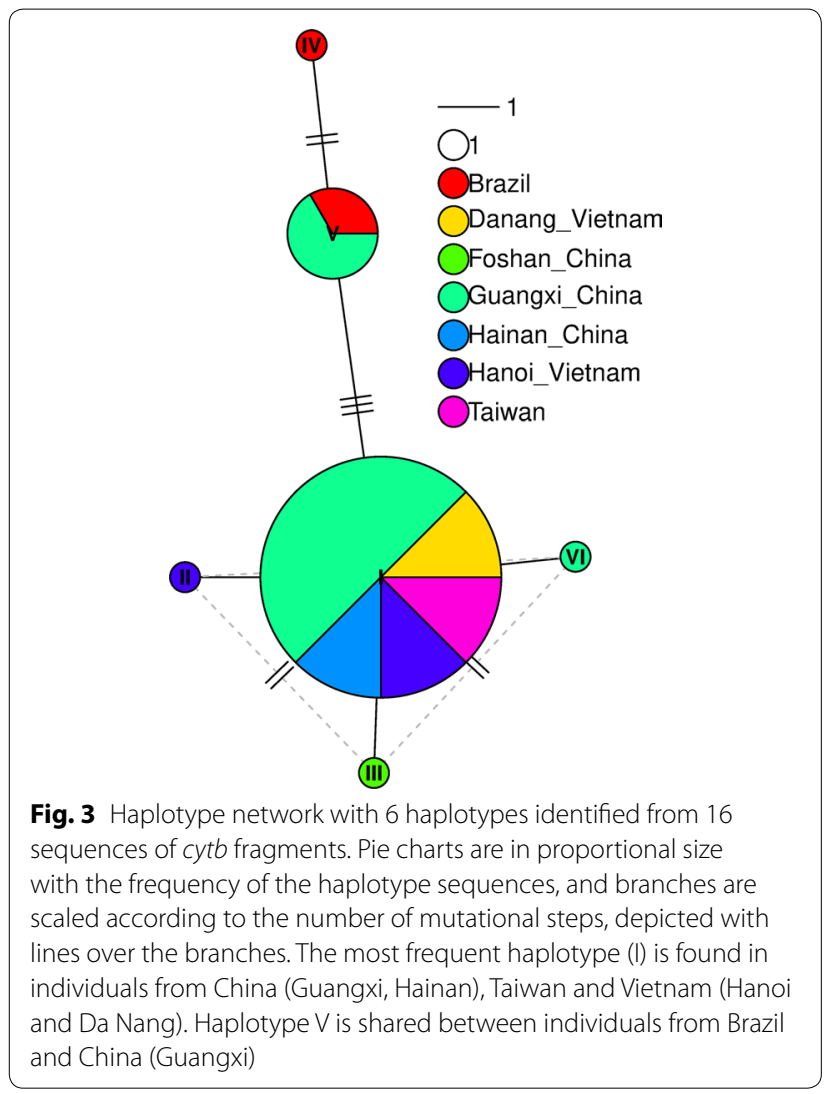

embryos or death of the embryo during its development (Fig. 4f). The eggs of T. rubrofasciata had a very high hatching rate; close to $98 \%$ (900 eggs, 882 nymphs of the first-instar). A female of $T$. rubrofasciata can produce eggs at any time of the year but the number of eggs gradually increased from January to July (on average 144 eggs per female), while it gradually decreased until reaching its lowest in December (on average 53 eggs per female). A single female can produce a minimum of 47 eggs and a maximum of 157 eggs.

\section{Life-cycles}

Figure 5 shows the minimum and maximum durations expressed in days for egg hatching and resistance to starvation of T. rubrofasciata. At least 10 days are required for eggs to hatch and a maximum of 32 days (lower temperatures during winter). Resistance to starvation increased in accordance with the stage of development, except for the adult bugs that presented resistance similar to the third-stage nymphs. After hatching, first-stage nymphs were able to survive for approximately $2-3$ weeks without blood meals. Fourth-stage nymphs showed the most resistance to starvation, since they could stay for a minimum of 38 days and a maximum of 120 days after molting without food. The lowest resistance was observed in the first-stage nymphs and the longest in the third-stage nymphs (Fig. 5). Life-cycles (newly produced eggs until death of adults) varied from 121 to 394 days. In addition, a minimum of 82 days and a maximum of 256 days were required for viable eggs to reach adulthood.

\section{Mortality rate of each nymphal stage}

The mortality rate of each nymphal stage was analyzed from an initial population of 300 first-stage nymphs. The mortality rate of each nymphal stage was relatively low, always lower than $10 \%$ except for the second- to the third-instar (17\%) (Fig. 6). An accumulated mortality rate of $33.7 \%$ was observed from the first-instar to the adult.

\section{Feeding capacity}

The weight of blood that nymphs could ingest in a single meal was greater than their own unfed weight (Fig. 7). All nymph stages increased almost thrice or more their own weight, specifically nymphs of the fifth-instar which presented a greater feeding capacity. In adults, regardless of sex, this relationship decreases significantly, representing only $68 \%$ of their own weight.

\section{Natural and experimental infection with Trypanosoma species}

A total of 100 adult bugs collected in domestic and peridomestic environments were examined. Of these, 37 were infected with Tryp. conorhini only, 18 were infected with Tryp. lewisi only and 9 were infected with both parasites. In conclusion, $64 \%$ of the insects examined were infected by at least one species of Trypanosoma. On the other hand, 180 nymphs in the first-stage (N1), divided into 6 groups, were experimentally infected with Tryp. conorhini and Tryp. lewisi by feeding them on infected mice in a single meal. Then the insects continued to be fed on live chickens once a week until they were sacrificed. The first group (N1) was sacrificed one week after the initial infection and each of the 5 remaining groups were sacrificed when they reached the different nymphal stages (N2, N3, N4 and N5) and adulthood, respectively. The parasite analysis of each group showed that $100 \%$ of the insects kept the parasites throughout their lives.

\section{Discussion}

Triatoma rubrofasciata presents several characteristics in the antennas, head and thorax that make them easily distinguishable from the other triatomine species [1]. In addition to corroborating the presence of these traits, we used genetic markers to confirm that the individuals collected in central Vietnam belong to T. rubrofasciata. At the chromosomal level, of almost 100 triatomine 

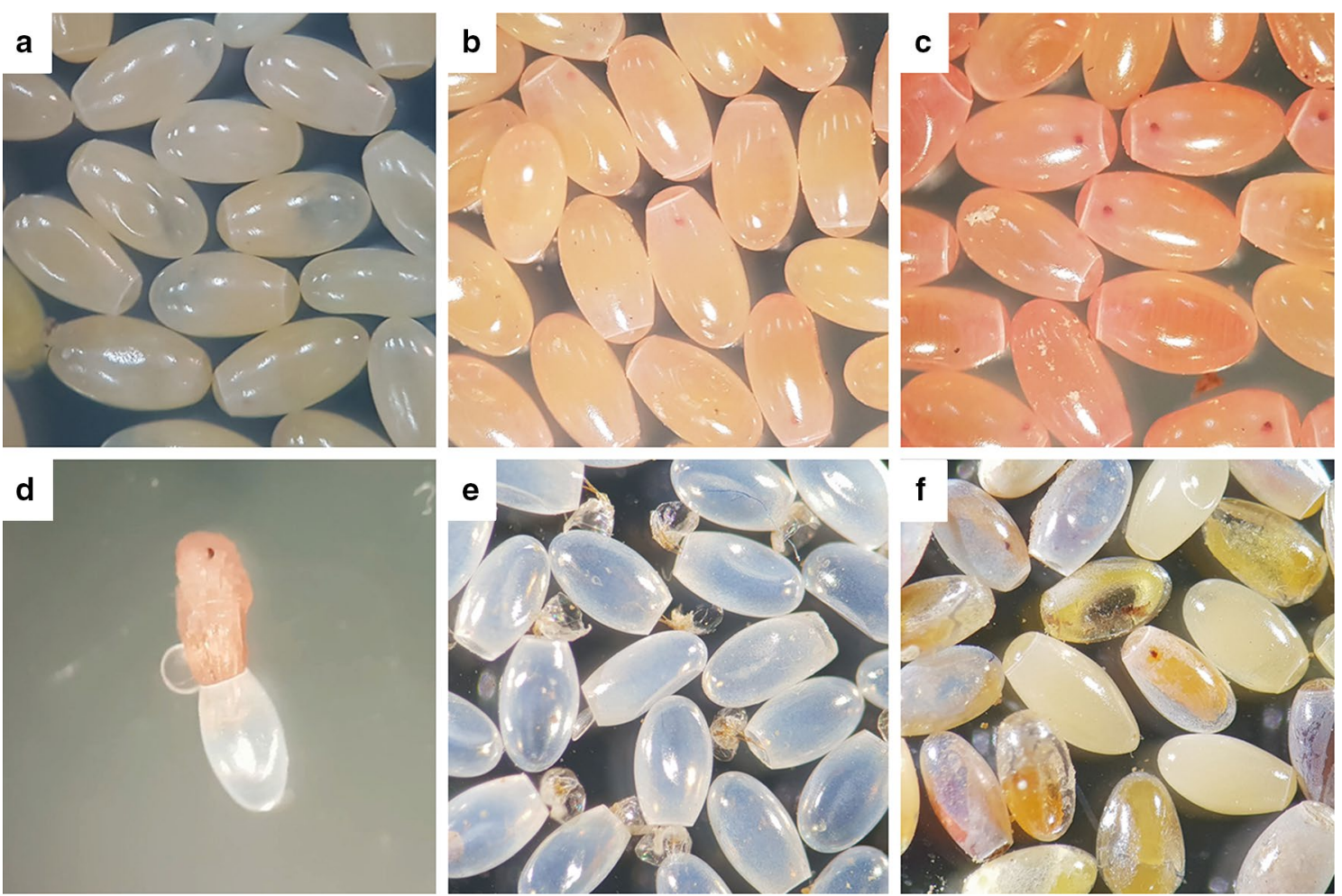

Fig. 4 Eggs of Triatoma rubrofasciata before and after hatching. a Newly produced eggs. b Eggs in the middle of their development. $\mathbf{c}$ Eggs before hatching. $\mathbf{d}$ Nymph emerging from the egg. e Empty fertile eggs. $\mathbf{f}$ Non-viable eggs (without hatching)

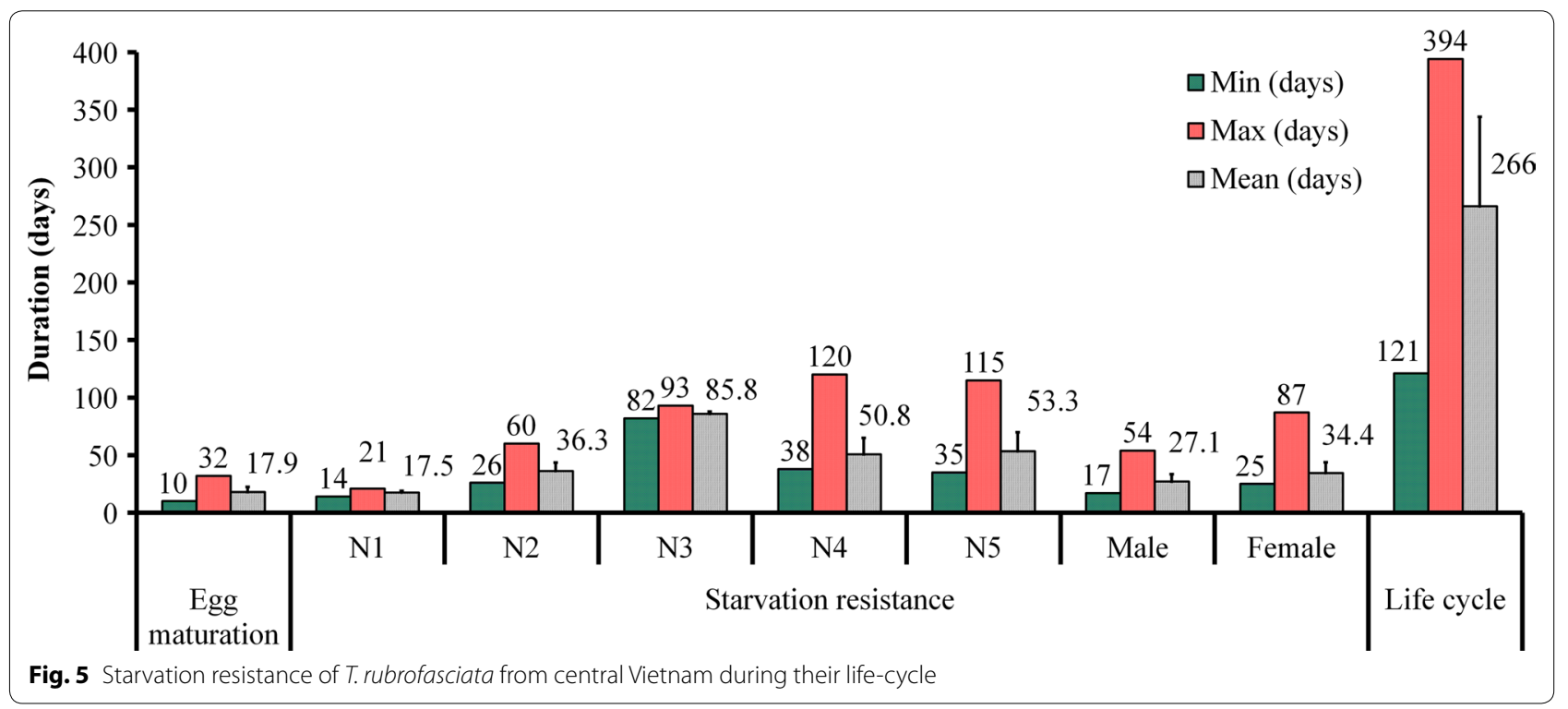

species cytogenetically described [30], only T. rubrofasciata has 22 autosomes, which we observed in all of the individuals analyzed (Fig. 2). Other chromosomal characteristics, such as the position, size and amount of C-heterochromatin, and the chromosomal position of ribosomal clusters are similar in individuals from Brazil and Vietnam (south and central) (present study and [13]).

By analyzing a partial fragment of the mitochondrial $c y t b$ gene, including all sequences available on GenBank $[6,13$, 31] and the two individuals here studied, we were able to 


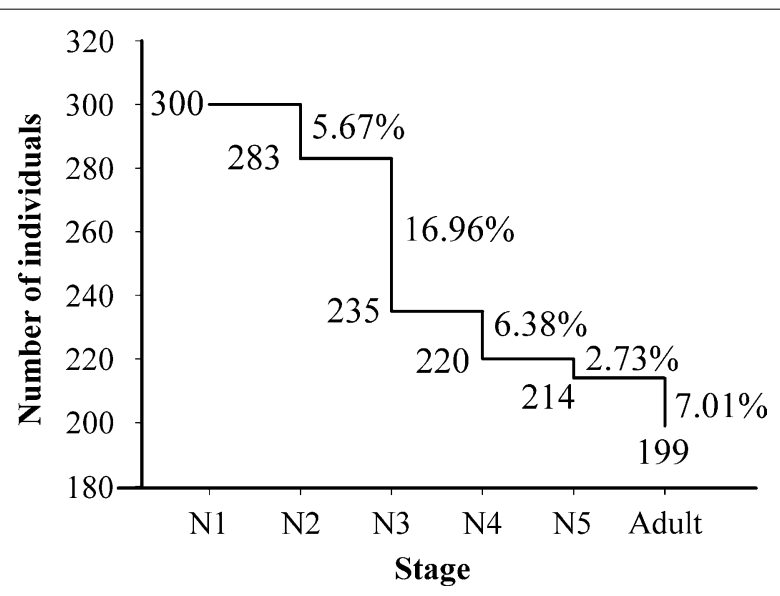

Fig. 6 Mortality rate in all nymph stages of T. rubrofasciata from central Vietnam. Numbers indicate initial number of bugs, and percentages indicate mortality rate before molting

determine the existence of six haplotypes corresponding to 16 individuals (4 from Vietnam, 2 from Brazil, 1 from Taiwan, 9 from South China) (Fig. 3). These haplotypes exhibit very low genetic distances (Additional file 1: Tables S1, S2), being compatible with expected levels of intraspecific variation. Furthermore, one of these haplotypes was shared between China and Brazil. This can be only explained by recent migration events. Tropicopolitan distribution of $T$. rubrofasciata is mainly explained by migration associated with their host, Rattus rattus, on commercial ships during the last 500 years [32-35]. Two very different hypotheses have been formulated about the evolutionary origin of $T$. rubrofasciata [3, 32-36]. The first hypothesis suggests that all Old World triatomines descend from a common ancestor that arrived in Eurasia from North America through the Bering Land Bridge about 20 million years ago. Therefore, T. rubrofasciata would have an Asian origin and its presence in the Americas would be the result of recent migrations $[3,36]$. The alternative hypothesis is that all Old World triatomine species derive from a single modern species, $T$. rubrofasciata, which was transported from the Americas to Asia in commercial ships from the 16th-17th centuries [3, 32-35]. Our data with cytb sequences showed a high genetic similarity suggesting a common and recent origin of the Asian (Vietnam, China) and American populations (Brazil). Similar results were recently shown using other nuclear $(28 \mathrm{~S}$ rDNA) and mitochondrial (16S rDNA and cox1) markers [8]. Furthermore, the low genetic variation between Tryp. conorhini from Brazil and Hawaii also supports a recent migration event [37]. An extensive population analysis which includes individuals from other regions such as India, Indonesia as well as the Caribbean islands would be necessary in order to evaluate the two hypotheses (Asian versus American) regarding the origin of T. rubrofasciata [36].
In central Vietnam, T. rubrofasciata is present in domestic environments and their surroundings, and apparently absent in wild habitats despite the various searches that were carried out. Until now, T. rubrofasciata has never been reported occupying wild habitats in both the Americas and Asia [36]. In big cities, this species has the capacity to inhabit houses of good construction quality, having the inhabitants as the main source of food. In these cases, the insects are concentrated in the lower floors of the buildings $(82 \%$ on the ground and first floors), probably due to their limited flight capacity (Fig. 1). In peridomestic habitats, both in urban and rural areas, T. rubrofasciata has always been associated with wood, both in firewood storage places as well as walls or ceilings of human constructions. All stages of the bugs were collected throughout the year revealing that their reproductive activity is not restricted to a particular season.

The average and maximum number of eggs that a female of T. rubrofasciata from central Vietnam produces (47 and 157 eggs, respectively) were lower than those reported for the species in Brazil (243 and 410 eggs, respectively) under similar feeding conditions [38]. However, the minimum time for eggs to hatch was 10 days, shorter than that reported for T. rubrofasciata from Brazil (16 days) and for other triatomine species [39]. These differences could be due to uncontrolled environmental conditions in our laboratory, especially in summer with temperatures above $35{ }^{\circ} \mathrm{C}$ and relative humidity greater than $75 \%$. From the study of 900 eggs, the hatching rate was almost $98 \%$, a value much higher than that observed in individuals from Brazil (80.5\%) [38] or in other evolutionarily close species such as T. gerstaeckeri (75\%), $T$. lecticularia (82.5\%) and T. protracta (76\%) [39].

From the analysis of 300 nymphs in the first stage (N1), 199 adults were obtained, with a mortality rate of $33.7 \%$ (Fig. 6). This mortality is a little higher than that observed in T. rubrofasciata from Brazil (24.6\%) where $179 \mathrm{~N} 1$ resulted in 135 adults [38]. The time required from hatching of eggs to adult varies between 82 and 256 days, very similar to those observed in Brazil (83 and 246 days). Comparatively with other triatomines species, T. rubrofasciata (found in Vietnam and Brazil) requires much less time to complete its life-cycle than other species of triatomines, such as Meccus picturatus (173 days), which feeds on chickens, or T. gerstaeckeri (255 days), T. lecticularia (201 days) and T. protracta (196 days) which feed on rabbits $[39,40]$.

Our results on resistance to starvation (Fig. 5) show that the specimens from Vietnam have a greater fasting capacity than Brazilian specimens [41]. However, this comparison should be considered with caution since the breeding conditions, especially the food sources, were 


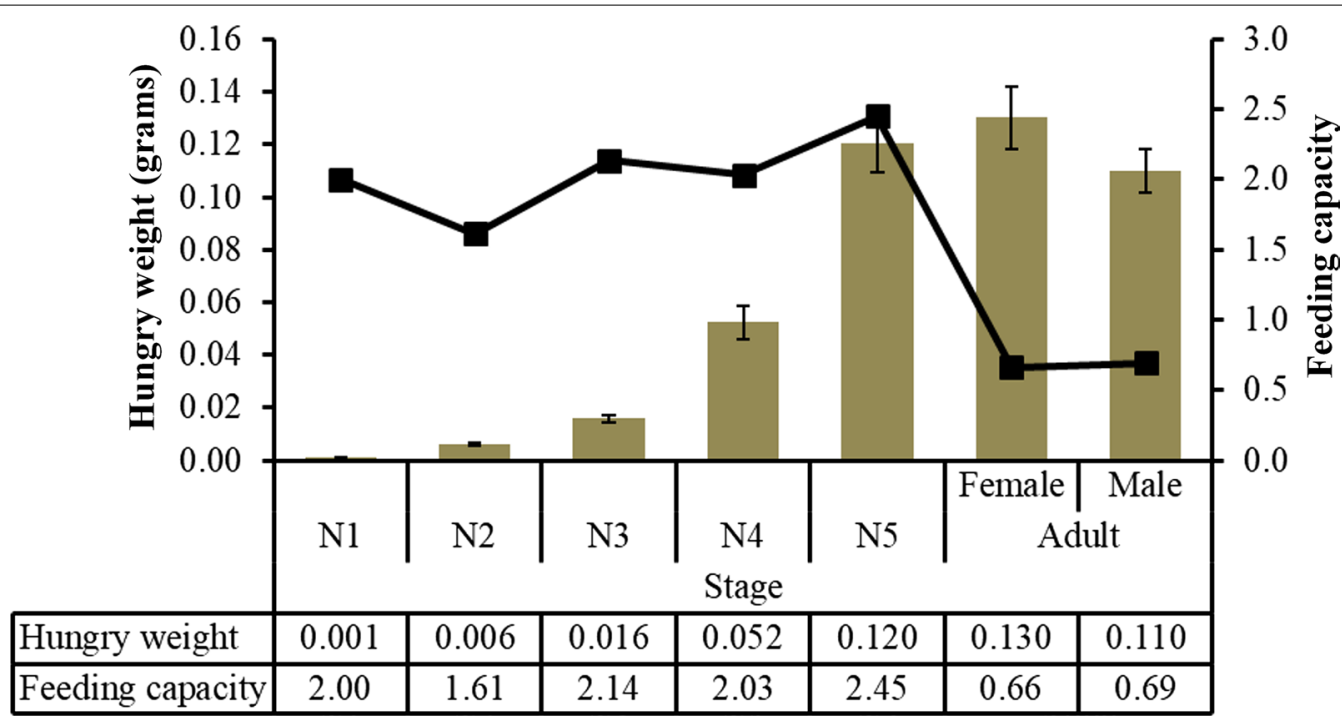

Fig. 7 Bugs' unfed weight (bars) and ratios of blood weights in first meal of bugs compared to their own unfed weight (line)

different (chickens in Vietnam and rats in Brazil). The nymphal stages have maximum periods of starvation between 60 and 120 days (except for nymph stage 1 with 3 weeks). These long periods would facilitate their dispersion by passive transport and the persistence of infestations in domiciles as well as in temporarily abandoned dwellings, similar to that described in $R$. prolixus [42].

The blood-feeding capabilities of the nymphs were surprisingly high (Fig. 7). Similar to the data reported for $T$. rubrofasciata in India [43], each nymphal instar increased its own weight two-fold, with the fifth-instar showing the greatest increase in weight (Fig. 7), which is typical in insects [44]. In adults, regardless of sex, this relationship decreased significantly, representing only $68 \%$ of their own weight. In addition, insects were able to survive for a long time without food. The values of blood meal in adults were similar to that reported for T. patagonica (65\% of their weight for females) [45]. Similar to Brazilian [46] and Indian T. rubrofasciata [47], this species from Vietnam showed natural infections with Tryp. conorhini (46\%). To the best of our knowledge, this study reports for the first time a natural infection of triatomine insects with Tryp. lewisi (27\%), a pathogenic parasite for humans which could represent an important burden on human health [21]. Triatoma rubrofasciata had a very high natural infection rate with $64 \%$ of the bugs infected by at least one Trypanosoma species.

\section{Conclusions}

This study showed that $T$. rubrofasciata has the capacity to invade human dwellings in urban areas of big cities in central Vietnam, using the inhabitants of the houses as a food source. In peridomestic environments of urban and rural areas, this species is mainly associated with wood structures and stored wood, which are very common in several Asian countries. Triatoma rubrofasciata has a fairly short life-cycle under uncontrolled laboratory environmental conditions, probably very similar to those found in their natural habitats. Their high rate of fecundity throughout the year, high capacity for starvation, as well as the occurrence of this species in synanthropic environments with high availability of food sources (in the case of Vietnam, rats, mice and chickens) are risk factors to be considered by vector control campaigns. Finally, several allergic reactions caused by the bites of $T$. rubrofasciata and their high infection with Tryp. lewisi underline the importance of analyzing its vector role and impact on human health.

\section{Supplementary information}

Supplementary information accompanies this paper at https://doi. org/10.1186/s13071-019-3844-6.

Additional file 1: Table S1. Basic population statistics of T. rubrofasciata sequences available on GenBank. Abbreviations: Nh, number of haplotypes; Hd, haplotype diversity; Nucl. div., nucleotide diversity ( $\pi$ ). Table S2. Genetic distances among the 6 haplotypes of T. rubrofasciata worldwide, calculated under Kimura 2-parameter model.

\section{Abbreviations}

cox1: cytochrome c oxidase subunit 1 gene; cytb: cytochrome b gene; PCR: polymerase chain reaction.

\section{Acknowledgements}

The authors acknowledge Dr. Jean Pierre Dujardin for critical reading of the manuscript. We are very grateful to Alejandra Panzera and Adam Franklin Johnson for their assistance with the language review. 


\section{Authors' contributions}

HVH, LTD, HH, PAT and TPM curated the data. HVH, LTD, SP, HH, PTK, PAT, TPM, NGL and FP carried out the investigation. LTD, PTK and FP supervised the work. HVH, LTD, SP, NGL and FP wrote the original draft of the manuscript. All authors read and approved the final manuscript.

\section{Funding}

This study was funded by Duy Tan University (Da Nang, Vietnam) and by project grants (No. 160) from the "Comisión Sectorial de Investigación Científica" (CSIC-Udelar-Uruguay). The funders had no role in study design, data collection, analysis, decision to publish, or preparation of the manuscript.

\section{Availability of data and materials}

All relevant data are within the article and its additional file.

\section{Ethics approval and consent to participate}

Not applicable.

\section{Consent for publication}

Not applicable.

\section{Competing interests}

The authors declare that they have no competing interests.

\section{Author details}

${ }^{1}$ Department of Medical Microbiology and Parasitology, Faculty of Medicine, Duy Tan University, Da Nang 550000, Vietnam. ${ }^{2}$ Institute for Global Health Innovations, Duy Tan University, Da Nang 550000, Vietnam. ${ }^{3}$ Sección Genética Evolutiva, Facultad de Ciencias, Universidad de la República, 11400 Montevideo, Uruguay. ${ }^{4}$ Department of Cell Biology, University of Science, Vietnam National University, Hanoi 100000, Vietnam.

\section{Received: 23 Auqust 2019 Accepted: 9 December 2019}

Published online: 16 December 2019

\section{References}

1. Lent $H$, Wygodzinsky P. Revision of the Triatominae (Hemiptera: Reduviidae) and their significance as vectors of Chagas disease. Bull Am Mus Nat Hist. 1979:163:125-520.

2. Ryckman RE, Archbold EF. The Triatominae and Triatominae-borne trypanosomes of Asia, Africa, Australia and the East Indies. Bull Soc Vector Ecol. 1981;6:143-66

3. Dujardin JP, Truong-Xuan L, Pham-Thi K, Schofield CJ. The rising importance of Triatoma rubrofasciata. Mem Inst Oswaldo Cruz. 2015;110:319-23.

4. Silveira AC, Martins E. Histórico do controle da transmissão vetorial e situação epidemiológica atual. Chapter 2. In: Galvão C, editor. Vetores da Doença de Chagas no Brasil. Curitiba: Sociedade Brasileira de Zoologia; 2014. p. 10-32. http://books.scielo.org/id/mw58j. Accessed 12 Jan 2019.

5. Bérenger JM, Pluot-Sigwalt $D$, Pagès F, Blanchet $D$, Aznar $C$. The Triatominae species of French Guiana (Heteroptera: Reduviidae). Mem Inst Oswaldo Cruz. 2009:104:1111-6.

6. Liu Q, Guo YH, Zhang Y, Zhou ZB, Zhang LL, Zhu D, Zhou XN. First records of Triatoma rubrofasciata (De Geer, 1773) (Hemiptera, Reduviidae) in Foshan, Guangdong Province, southern China. Infect Dis Poverty. 2017;6:129.

7. Huang YL, Huang DN, Wu WH, Yang F, Zhang XM, Wang M, et al. Identification and characterization of the causative triatomine bugs of anaphylactic shock in Zhanjiang, China. Infect Dis Poverty. 2018;7:127.

8. Hu Y, Gao MZ, Huang P, Zhou HL, Ma YB, Zhou MY, et al. Taxonomic integrative and phylogenetic identification of the first recorded Triatoma rubrofasciata in Zhangzhou, Fujian Province and Maoming, Guangdong Province, China. Infect Dis Poverty. 2019;8:70.

9. Claver MA, Yaqub A. Morphometric analysis of tropicopolitan bug Triatoma rubrofasciata (De Geer) in two different parts of India. Int J Res Stud Biosci. 2015:3:130-8.

10. De Silva NR, Dasanayake WMDK, Karunatilake C, Wickramasingha GD, De Silva BD, Malavige GN. Aetiology of anaphylaxis in patients referred to an immunology clinic in Colombo, Sri Lanka. Allergy Asthma Clin Immunol. 2018;14:18

11. Teo SK, Cheah JS. Severe reaction to the bite of the triatomid bug (Triatoma rubrofasciata) in Singapore. J Trop Med Hyg. 1973;76:161-2.

12. Anderson C, Belnap C. The kiss of death: A rare case of anaphylaxis to the bite of the "red margined kissing bug". Hawaii J Med Public Health. 2015;74:33-5.

13. Dujardin JP, Pham Thi K, Truong Xuan L, Panzera F, Pita S, Schofield CJ. Epidemiological status of kissing-bugs in South East Asia: a preliminary assessment. Acta Trop. 2015;151:142-9.

14. Vieira CB, Praça YR, Bentes KLS, Santiago PB, Silva SMM, Silva GS, et al. Triatomines: trypanosomatids, bacteria, and viruses potential vectors? Front Cell Infect Microbiol. 2018;8:405.

15. Lin RH, Lai DH, Zheng LL, Wu J, Lukeš J, Hide G, Lun ZR. Analysis of the mitochondrial maxicircle of Trypanosoma lewisi, a neglected human pathogen. Parasit Vectors. 2015;8:665.

16. Bradwell KR, Koparde VN, Matveyev AV, Serrano MG, Alves JMP, Parikh H, et al. Genomic comparison of Trypanosoma conorhini and Trypanosoma rangeli to Trypanosoma cruzi strains of high and low virulence. BMC Genomics. 2018;19:770.

17. Hoare CA. The trypanosomes of mammals. A zoological monograph. Oxford: Blackwell Scientific Publications; 1972

18. Deane MP, Deane LM. Studies on the life cycle of Trypanosoma conorrhini. "In vitro" development and multiplication of the bloodstream trypanosomes. Rev Inst Med Trop São Paulo. 1961;3:149-60.

19. Deane LM, Deane MP, Lourenco-de-Oliveira R. Are Asian monkeys the original mammalian hosts of Trypanosoma conorhini? Mem Inst Oswaldo Cruz. 1986;81:127-9.

20. Durden LA, Hinkle NC. Fleas (Siphonaptera). In: Mullen GR, Durden LA, editors. Medical and veterinary entomology. 3rd ed. London: Academic Press; 2019. p. 145-69.

21. Truc P, Buscher P, Cuny G, Gonzatti MI, Jannin J, Prashant J, et al. Atypical human infections by animal trypanosomes. PLoS Negl Trop Dis. 2013;7:e2256

22. Bharodiya D, Singhal T, Kasodariya GS, Banerjee PS, Garg R. Trypanosomiasis in a young infant from rural Gujarat, India. Indian Pediatr. 2018;55:69-70.

23. Doke PP, Kar A. A fatal case of Trypanosoma lewisi in Maharashtra. India. Ann Trop Med Public Health. 2011;4:91-5.

24. Panzera F, Alvarez F, Sanchez-Rufas J, Pérez R, Suja JA, Scvortzoff E, et al. C-heterochromatin polymorphism in holocentric chromosomes of Triatoma infestans (Hemiptera: Reduviidae). Genome. 1992;35:1068-74.

25. Panzera Y, Pita S, Ferreiro MJ, Ferrandis I, Lages C, Pérez R, et al. High dynamics of rDNA cluster location in kissing bug holocentric chromosomes (Triatominae, Heteroptera). Cytogenet Genome Res. 2012:138:56-67.

26. Monteiro FA, Wesson DM, Dotson EM, Schofield CJ, Beard CB. Phylogeny and molecular taxonomy of the Rhodniini derived from mitochondrial and nuclear DNA sequences. Am J Trop Med Hyg. 2000;62:460-5.

27. Katoh K, Standley DM. MAFFT Multiple sequence alignment software version 7: improvements in performance and usability. Mol Biol Evol. 2013;30:772-80.

28. Paradis E, Claude J, Strimmer K. APE: analyses of phylogenetics and evolution in R language. Bioinformatics. 2004;20:289-90.

29. Paradis E. Pegas: an R package for population genetics with an integrated modular approach. Bioinformatics. 2010;26:419-20.

30. Panzera F, Pérez R, Panzera Y, Ferrandis I, Ferreiro MJ, Calleros L. Cytogenetics and genome evolution in the subfamily Triatominae (Hemiptera, Reduviidae). Cytogenet Genome Res. 2010;128:77-87.

31. Dong L, Ma X, Wang M, Zhu D, Feng Y, Zhang Y, Wang J. Complete mitochondrial genome of the Chagas disease vector, Triatoma rubrofasciata. Korean J Parasitol. 2018;56:515-9.

32. Schofield CJ. Biosystematics of the Triatominae. In: Service MW, editor. Biosystematics of haematophagous insects. Oxford: Clarendon Press; 1988. p. 285-312

33. Gorla DE, Dujardin JP, Schofield CJ. Biosystematics of Old World Triatominae. Acta Trop. 1997;63:127-40.

34. Dujardin JP, Schofield CJ, Panzera F. Les Vecteurs de la Maladie de Chagas: Recherches taxonomiques, biologiques et Génétiques. Brussels: Academie Royale des Sciences d'Outre-Mer; 2000. 
35. Patterson JS, Schofield CJ, Dujardin JP, Miles MA. Population morphometric analysis of the tropicopolitan bug Triatoma rubrofasciata and relationships with Old World species of Triatoma: evidence of New World ancestry. Med Vet Entomol. 2001;15:443-51.

36. Monteiro FA, Weirauch C, Felix M, Lazoski C, Abad-Franch F. Evolution, systematics, and biogeography of the Triatominae, vectors of Chagas disease. Adv Parasitol. 2018;99:265-344.

37. Espinosa-Álvarez O, Ortiz PA, Lima L, Costa-Martins AG, Serrano MG, Herder S, et al. Trypanosoma rangeli is phylogenetically closer to Old World trypanosomes than to Trypanosoma cruzi. Int J Parasitol. 2018;48:569-84.

38. Braga MV, Pinto ZT, Lima MM. Life cycle and reproductive patterns of Triatoma rubrofasciata (De Geer, 1773) (Hemiptera: Reduviidae), under laboratory conditions. Mem Inst Oswaldo Cruz. 1998;93:539-42.

39. Martínez-Ibarra JA, Alejandre-Aguilar R, Paredes-González E, MartínezSilva MA, Solorio-Cibrián M, Nogueda-Torres B, et al. Biology of three species of North American Triatominae (Hemiptera: Reduviidae: Triatominae) fed on rabbits. Mem Inst Oswaldo Cruz. 2007;102:925-30.

40. Martínez-Ibarra JA, Novelo-López M, Hernández-Robles MR, Grant-Guillén Y. Influence of the blood meal source on the biology of Meccus picturatus Usinger 1939 (Hemiptera: Reduviidae: Triatominae) under laboratory conditions. Mem Inst Oswaldo Cruz. 2003;98:227-32.

41. Rojas-Cortéz MG, Gonçalves TCM. Resistance to starvation of Triatoma rubrofasciata (De Geer, 1773) under laboratory conditions (Hemiptera: Reduviidae: Triatominae). Mem Inst Oswaldo Cruz. 1998;93:549-54.
42. Feliciangeli D, Rabinovich J, Fernández E. Resistencia al ayuno en triatominos (Hemiptera, Reduviidae) venezolanos. I. Rhodnius prolixus Stål. Rev Inst Med Trop São Paulo. 1980;22:53-61.

43. Ambrose DP, Rajan K. Food requirements of the nymphal instars of Triatoma rubrofasciata De Geer (Hemiptera: Reduvidae). J Adv Zool. 1992;13:40-5.

44. Chapman RF. Postembryonic development. In: Simpson SJ, Douglas AE, editors. The insects: structure and function. 5th ed. Cambridge: Cambridge University Press; 2013. p. 398-462.

45. Nattero J, Crocco LB, Rodríguez CS. Feeding and defaecation behaviour of Triatoma patagonica (Del Ponte, 1929) (Hemiptera: Reduviidae). Mem Inst Oswaldo Cruz. 2002;97:1063-5.

46. Dias E, Seabra CAC. Sôbre o Trypanosoma conorrhini, hemoparasito do rato transmitido pelo Triatoma rubrofasciata: presença do vector infectado na cidade do Rio de Janeiro. Mem Inst Oswaldo Cruz. 1943;39:301-29.

47. Haridass ET, Ananthakrishnan TN. Bionomics and behaviour of the reduviid bug, Triatoma rubrofasciata (De Geer), the vector of Trypanosoma (Megatrypanum) conorhini (Donovan) in India (Insecta: Heteroptera). Proc Indian Natn Sci Acad. 1981;B46:884-91.

\section{Publisher's Note}

Springer Nature remains neutral with regard to jurisdictional claims in published maps and institutional affiliations.
Ready to submit your research? Choose BMC and benefit from:

- fast, convenient online submission

- thorough peer review by experienced researchers in your field

- rapid publication on acceptance

- support for research data, including large and complex data types

- gold Open Access which fosters wider collaboration and increased citations

- maximum visibility for your research: over $100 \mathrm{M}$ website views per year

At BMC, research is always in progress.

Learn more biomedcentral.com/submissions 